\title{
Planning for a neighborhood and city-scale green network system in Qatar: the case of MIA Park
}

\author{
Raffaello Furlan $^{1}$ (D) B Brian R. Sinclair ${ }^{2}$
}

Received: 11 August 2020 / Accepted: 4 February 2021 / Published online: 5 March 2021

(c) The Author(s) 2021

\begin{abstract}
In the past decade, Doha has witnessed fast-urban growth, an increased population rate, and an over-reliance on the automobile as the main mode of urban transportation. These factors caused social and environmental problems related to (1) the loss of a compact urban pattern, (2) an increased level of air pollution (3) high traffic congestions and (4) increasing landscape fragmentation. In consideration of such concerns, The State of Qatar invested large funds into the urban landscape development of Doha, as envisioned by Qatar National Vision 2030. As a result, in the past five years various parks and/or green areas, such MIA Park, a major public green space located around the Museum of Islamic Art (MIA), were planned and developed within metropolitan Doha. The authors argue that this park is currently facing issues and challenges related to (1) accessibility to/from the neighboring districts, and (2) connectivity to/from the neighboring parks. Therefore, this research study aims at assessing the existing conditions of MIA Park, at considering the broader city context and, at recommending strategies for implementing MIA Park's green network system. It approached the investigative challenge using a multi-pronged comprehensive methodology, that deployed focus groups, semi-structured interviews and a comprehensive network analysis based on graph theory. The findings, revealed through these hybrid research tactics, allowed the researchers to generate a framework to enhance accessibility and connectivity of MIA Park through a green network system, planned at inter-related neighborhoodscale and city-scale levels. While the research examines most notably a single case, it is advocated that the proposed framework represents not just an optional feature pertaining to the case in Doha, but a valuable reference for the sustainable master planning of future cities in the State of Qatar and across the GCC. The paper proffers numerous key contributions, including the critical exploration of manufactured landscapes in Doha Qatar and the delineation of broadly applicable environmental design strategies to improve the fabric and livability of cities.
\end{abstract}

Keywords Green urban spaces · Landscape fragmentation · Urban fabric · MIA Park [Doha] $\cdot$ Graph theory $\cdot$ Green network system

Raffaello Furlan

raffur@gmail.com; rfurlan@qu.edu.qa

Extended author information available on the last page of the article 


\section{Introduction}

As the human body grows as one entity shaped by different apparatus \& appendages, so to do cities expand as one entity shaped by and incorporating different aspects and components. City planning and community building, including landscape design, demand a system understanding and comprehensive strategies. In the body our arteries and veins (the network) need to flow blood and other required nutrients to all of the system's components, such as the skeleton, muscles, organs, etc. The individual parts must all function well to ensure the body can build-up, operate effectively and retain health. Body parts of the same organism do not grow individually and then get connected: they grow up interconnected, simultaneously, in the most fascinating, efficient and integrated natural process (Bacon 1967; Kostof 1991).

Likewise, a city as a whole cannot be viewed to as single discrete and detached plots of land, separate buildings and disconnected infrastructures developed in isolation, and then assembled together at the end. Scholars and researchers argue the need for the city to simultaneously develop its functional spaces, buildings and infrastructure interactively as a well-connected system rather than as fragmented pieces (Rossi 1984). Notably, the public realm (e.g., plazas, green areas, streetscapes, etc.) must to be perceived as spatial elements to be planned as the built environment's coagulant [i.e., through effective planning policies and integrative masterplans by authorities and municipalities]. Our urban spaces and landscapes are not merely the voids between buildings - rather they provide the arena for vibrancy and key ingredients contributing to quality of life (Furlan and Sipe 2017; Furlan et al. 2020; Gehl 2011; Gehl and Svarre 2013; Morris 1979).

On the other hand, scholars looking at cities contend that in practice green spaces are often perceived as abandoned or neglected pieces of land, not well integrated within the built environment of cities, and not perceived as active vital nodes within the urban fabric (Beatley 2000; Beatley and Newman 2009). The authors argue such neglect transpires when planning is conducted as piecemeal exercises rather than as a holistic enterprise. Scholars stress the importance of managing the urban expansion of a city through dynamic processes of crafting an integrated spatial/functional system. However, only a few studies have offered detailed and efficient approaches for integrating public realms into a cohesive urban space system and for reducing existing fragmentation within metropolitan spatial form (Haas 2012). Based on this need, the present study investigates the extent to which the spatial model for the urban green network of a single park in Doha can be meaningfully analyzed, implemented, better understood, and built upon.

In the second half of the twentieth century, Qatar experienced its first modern urbanization period which occurred as a result of the rapid increase in the production capacity of natural gas and oil accompanied by active and lucrative oil markets. In turn, Qatar's economy transformed from an economy based on fishing and pearling into a robust multifaceted economy. Between 2000 and 2009, Qatar's real GDP grew at an annual average of 13.1\% (AL-Mohannadi et al. 2020; Furlan and Harami 2020; Steiner 2011). Consequently, the prosperity and growth of Qatar's economic status led to the implementation of several important urban developments and megaprojects such as Katara, the Pearl and Hamad international airport, in addition to various satellite projects such as Lusail city, Msheireb Downtown Doha, Education city, Hamad Medical City, Economic Zone 1, Al Waab City, etc. (Elsheshtawy 2008; Salama and Wiedman 2013) (Fig. 1a; Furlan and Al Thani 2020).

In the past decade, this rapid urban development, along with population growth and heightened consumption levels caused major changes to Qatar's built environment and 

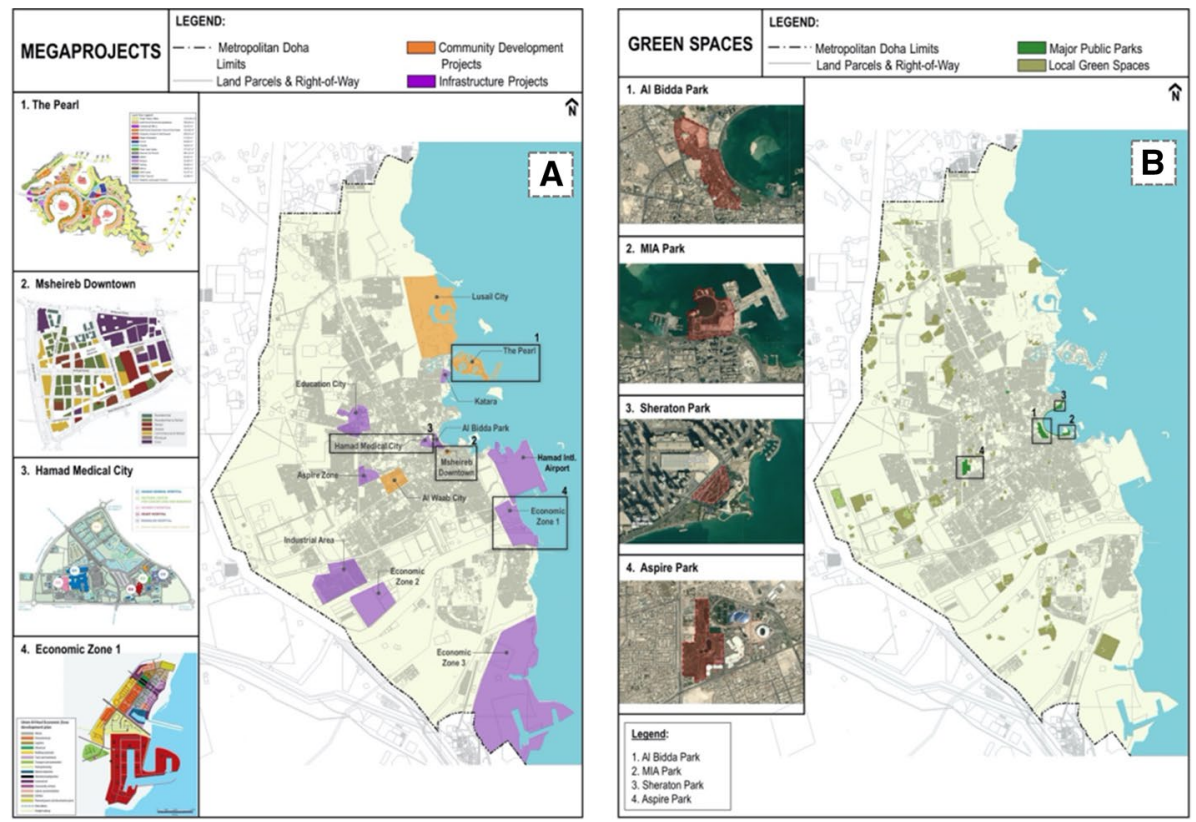

Fig. 1 Metropolitan Doha: a Megaprojects and b Green Spaces. Source: The Authors

urban landscape, mainly related to poorly distributed green spaces that lacked connectivity throughout Doha's urban fabric (Fig. 1b). Accordingly, in 2008 and 2014, Qatar governmental agencies launched Qatar National Vision 2030 (QNV-2030) and Qatar National Development Framework 2032 (QNDF-2032), aiming at formulating a national framework to guide metropolitan and regional built environmental developments, based on principles of sustainability and green urbanism (Furlan et al. 2019; MME 2008; Tannous et al. 2021).

Therefore, as envisioned by Qatar National Vision 2030 (QNV-2030), the State of Qatar invested large funds into urban landscape development of Doha, including efforts to reduce the metropolitan landscape fragmentation. Private sector and government authorities actively embraced an urban development approach for the integration of green areas throughout the urban fabric of Doha. Such initiatives resulted in planning for various regional and large parks/gardens within metropolitan Doha, such as the Al Bidda Park, the Museum of Islamic Art (MIA) Park, Sheraton Park, Aspire Park and others (Furlan and AL-Mohannadi 2020).

The Museum of Islamic Art (MIA) Park, a major public green space located around the Museum of Islamic Art (MIA), is the flagship intervention highlighting the transformation of Qatar into the cultural capital of Middle East. The museum stands alone on an island surrounded by a park which spreads across more than 7 acres of land. MIA Park forms a crescent of inclined green space within Doha Bay. This curved crescent is an extension of Doha Corniche, which is defined as a direct link with other radial connectors, linking West Bay (New Business district of Doha) to the Souq Waqif (the preeminent heritage site of Doha) (Gunay 2003). MIA and its associated park location are strategized to avoid future encroachments and to represent the museum as a solid foundation of Qatari tradition and culture. 
Additionally, the surrounding area of the Corniche has accommodated several prestigious buildings such as the Emiri-Diwan, the Central Bank, the recently inaugurated National Museum of Qatar, and the Sheraton Hotel. Therefore, the museum stands as a landmark-an iconic cultural structure of cultural import yet quite isolated from regular city life (Hashem 2015). Therefore, MIA park which is supposed to act as a catalyst between the museum and city networks (green), also remains isolated.

This study argues that MIA Park is neither easily accessible at the neighborhood-scale level nor connected to the large network of green areas, at city-scale level. Based on this argument, this study investigates the existing conditions of MIA Park, to better understand the extent to which a spatial model of urban green network can be implemented, with the aim to enhance (1) accessibility to/from neighboring districts, and (2) connectivity to/from neighboring green areas. While accessibility can be defined as the spatial or territorial easiness by which people can reach a desired activity site, connectivity refers to movement among spatially distinct entities such as districts (Furlan et al. 2016; Jona 2018; Massicotte and Frenette 2011; Semm and Palang 2010).

The insights from this investigation (through the criteria of accessibility and connectivity) will contribute to develop a spatial model of urban green network (defined as the interactions between the nodes), aiming at reducing landscape fragmentation and at enhancing urban green areas' integration, based on (1) the neighborhood and (2) the city-scale. The researchers contend that through gaining an understanding of the challenges and opportunities around MIA Park, steps can be envisioned to better integrate vital urban space, including landscapes, as Doha and Qatar continue to evolve and improve.

\section{Literature review/study areas}

This section of the paper addresses general conceptual concerns about planning issues and challenges related to (1) Urban Green Networks, and (2) Qatar's urbanization process. The objective is to provide a framework for the study of the key factors, concepts and the presumed relationships among them, which in turn supports, informs and clarifies the phenomena investigated throughout this particular research study.

\subsection{Urban green areas and network: vital nodes integrated through the urban fabric}

Researchers and scholars have been arguing for the past 40 years concerning the criticality of reducing landscape fragmentation by planning and developing urban green spaces, accessible and interconnected within the metropolitan built environment (Jansson 2014).

"Green Cities: Good Health" concluded that people throughout the globe who live nearby green areas have high quality of life in comparison to the opposite (University and Washinghton 2018).

In turn, scholars argue how spatial network analysis represents the first step to identify the territorial-communication gaps and, in turn, to implement models of spatial and social network and/or dimension/extension based on localized geographical nodes (Massicotte and Frenette 2011; Semm and Palang 2010).

In 2008, a study from Peter H. Kahn from the Department of Psychology, Seattle, compared the levels of stress and mental health among the citizens that live nearby green areas 
versus the citizens living afar. The results revealed that people with low stress or people who recover better in any illness are those spending more time in parks/green areas and/ or connected with nature. The study also revealed that technology cannot replace nature and watching nature through digital medium is not as effective as being surrounded by a natural environment (Kahn et al. 2008). Nature is important to healthy city dwelling. A recent study by Christopher Black, from Department of Health and Urban Sustainability at World Health Organization (WHO), underscored that 3.3\% of global deaths are recorded due to physical inactivity, related to poor walkability and lack of access to recreational areas (Black 2016).

A similar study in 2019 revealed that access to green areas in cities reduces crime rates. The findings concluded that accessing nature has a mitigating impact on the crime and violence rates in an area. To ascertain the evidence, the University of Virginia Health System conducted an in-depth literature review using PRISMA checklist method. The findings extracted mechanisms that may account for high impact of crime rate that includes lack of social interaction, poor access to recreation, community perception, biophilic stress, and imbalance in climate. Such features can reduce the quality of life, or livability, in our cities. However, when such inadequacies are balanced out through providing urban green spaces in the community, a positive impact on reducing crime rates is noted (Shepley et al. 2019).

Urban green spaces, which included parks, gardens, meadows, and wetlands, prove to be significant for reinforcing and balancing urban ecosystems. Additionally, green spaces also contribute to cooling cities and to reducing the impact of heat island effects in dense urban settings (Oliveira 2017). A study by Kabisch and Bosch shows how unequal distribution of urban green spaces is directly proportional to ill health of its citizens. The researcher takes the case of the city of Berlin and maps out the metropolitan's greenest and least green areas. Another set of maps shows the prevalence of diseases and the average life expectancy of its citizens. Comparing both the maps, the study concludes that urban green spaces positively contribute to the well-being of city dwellers residing in the surroundings of such amenities (Kabisch and Bosch 2017).

Despite the importance of green urban areas integrated within the built environment of cities, planners have sometimes treated green spaces as outside of the civic equation-as unmanaged and abandoned pieces of land-simply because green spaces are not perceived as nodes and, hence, may not be used efficiently. This could be primarily because of lack of safety measures incorporated in such spaces, thereby discouraging the communities to efficiently utilize the greens. Perceptions can have debilitating consequences that may deny logic and defy the reality of a situation. The physical accessibility, as the generation of spaces for territorial access/communication for developing an urban ethos, and safety of landscapes is mainly an urban design and planning issue which can be tackled by providing high quality design to access and connect urban green spaces (Galderisi and Ceudech 2010; Wang and Gonzalez 2009). The nodes of the city connect communities (people), nature (greens) and wildlife (ecosystems) through corridors (Kevin Lynch 1960). These corridors define the smooth functioning of the city, that is, allowing people to safely reach their destinations in health-promoting ways, and, as a result, provide territorial meanings and different social constructive possibilities. These corridors, if not planned and/or designed well, negates the significance of nodes. Continuity and systems approaches are vital in such scenarios. Hence, the pragmatic solution to more efficiently activate civic nodes would be to prioritize the need for natural urban corridors (Roberts et al. 2017).

Many countries have policies in place to encourage city dwellers to visit green spaces, but in the past two decades, scholars studies have also highlighted the increasing disconnection of people to green spaces (Bell et al. 2018). Ian C. Mell, in his study on England's 


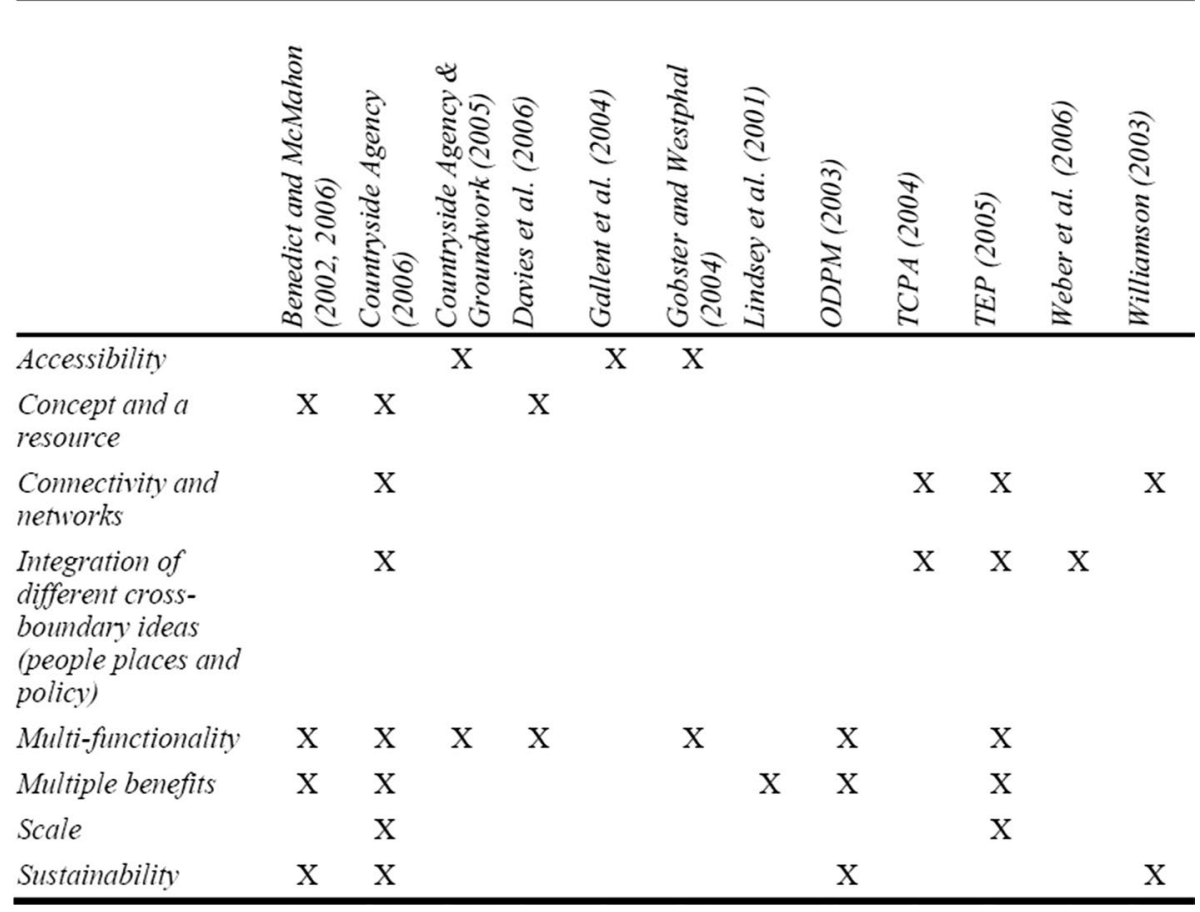

Fig. 2 Parameters to interlink vital nodes (green spaces) with built environment as perceived by scholars. Source: Mell 2017

community green spaces defined the parameters for successful green spaces (Fig. 2). It can be inferred that lack of accessibility, lack of planned networks (connectivity through corridors across the urban fabric) and lack of multi-functional use of place are due to land fragmentation, that is, green spaces that are developed or that have evolved into vacant plots-namely, such spaces have not been functionally nor physically integrated within the built environment. Figure 2 reveals the findings of his study as replicated from studies of various scholars, practitioners and researchers on the principles of green infrastructure (Mell 2017).

Integrating city "green nodes" through a green network that travels across a compact urban fabric has become an urban planning necessity (Gottdiener et al. 2019). A study developed in Dresden, Germany, highlighted how the development of modular concepts of green infrastructure contribute to structuring complex relationships between urban green spaces and the built environment. The guidelines developed through the analysis of the landscape plan for Dresden, reflects spatial heterogeneity of green spaces in the city and considers cities as integrated socio-ecological systems. Such a holistic perspective is crucial to the health of cities and their inhabitants. Therefore, the proposed guidelines promote the master planning for a more compact Dresden, inclusive of green infrastructure and embracing ecological parameters (Artmann et al. 2017).

A study published in 2019 in China led by Quanyi Zheng, considers the case of 22 municipal parks within 3 districts of Shenzhen. In terms of a planning approach, parks are constructed between gray infrastructures (depending upon the provision of land) 
and parks as a system are planned considering accessibility from gray infrastructures as well as connectivity to each other. Evidently, the study revealed that walking distance is one of the most significant parameters influencing the frequency with which parks are accessed by city dwellers. Traditionally, parks were planned to be accessible from the neighboring districts, and not from distant communities. Nevertheless, researchers are now revealing how urban green areas, accessible and connected through corridors with pedestrian paths and bicycle lanes are efficiently used by city dwellers residing in both the adjacent and in the peripherical districts (Zheng et al. 2019). Therefore, communities' accessibility and connectivity to/from green urban spaces is enhanced by efficiently distributed and interconnected green infrastructures.

A study by Hanna Olsson highlighted the significance of designing user-friendly urban green spaces by adding specific physical features. The study, focusing on two parks in South Bank Parklands and City Botanic gardens, in Brisbane Australia, discussed the implementation of a wide range of landscape design principles. Also, the author states that the success of the two parks is based on the ease of access from neighboring communities and, namely, by features enhancing the attractiveness of the park to the residents (Olsson 2012).

In her "Metro Green: Connecting Open Spaces in North American Cities," Donna Ericson compared successful urban green spaces located in Toronto, Calgary, Vancouver, Ottawa, Chicago, Denver, Portland, Minneapolis, Cleveland, and Milwaukee. The comparative analysis reveals that the level of attractiveness toward each park is graded based on the degree of enhanced social and ecological capital (Ericson 2012). A recent study at Heriot Watt University, UAE, also outlines the necessity of planning green spaces fulfilling ecological and, namely, recreational purposes and/or to enhance social interactions at a community level. In the UAE, green courtyards were a traditional feature of the 1960s urbanism, but recently their function was replaced by modern town squares. Therefore, scholars are arguing how green spaces should be re-planned as metropolitan urban nodes, linking people to nature, to reduce landscape fragmentation and enhance users' social capital (Ezzeddine and Kashwani 2019).

Based on the insights provided by the literature reviewed, this research study aims at investigating the existing conditions of one of the most significant green urban areas in Doha, namely MIA Park, to better understand the extent to a urban green network can be implemented by addressing challenges related to the park's (i) accessibility to/from neighboring districts, and (ii) connectivity to/from neighboring green areas. The findings revealed by this investigation will contribute to the development of a novel spatial model, aiming at enhancing the park's social-ecological capital and reducing landscape fragmentation at both the neighborhood and (ii) the city-scale level (Fig. 3).

SCOPE

FUNCTION

BENEFITS

HEALTH [AIR, WALKBAILITY, ETC]

CRIME - SAFETY - SECURITY

ECOLOGY

SOCIAL-ECOLOGICAL CAPITAL

SENSE OF SAFETY-SECURITY

PEDESTRIAN/CICLYING

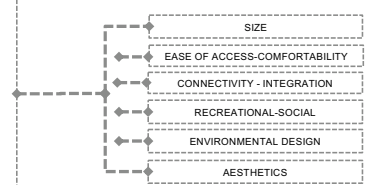

Fig. 3 Urban green areas and network, Source: The Authors 


\subsection{Qatar's urbanization}

In the mid-twentieth century, the revenue from an increased oil production led Qatar to its first urbanization period. From the 1950s to 1970, the revenue from oil resources stimulated the development of infrastructures and urban settlements, envisioned through on the automobile as the main mode of transportation, which in turn caused social, economic, and environmental challenges, and most notably traffic congestion, increased levels of air pollution, growing sprawl countering compact development, population growth, and loss of traditional urban fabric. Concerning city residents, Doha's population grew from around only 14,000 inhabitants to more than 83,000, with foreign immigrants constituting about 67\% of the entire population (Furlan 2019; Wiedmann et al. 2012).

Since the 1970s, Qatar witnessed rapid urban growth characterized by the emergence of mega-scale projects, star architecture, and new mixed-use developments, such as the Pearl Development, Lusail City, and Msheireb Downtown Doha (Fig. 1a). These projects followed the formulation of different national strategies that aim to diversify the national economy and which lead to a second urban transformation process. This massive transformation of a traditional community has seen the demolishing of green courtyards of the native inhabitants only to be replaced by compact urban growth aimed at meeting the needs of the increasing population. While change is to be expected as a city and nation grow, management of change should focus on preserving and enhancing quality of life (QoL) (Hashem 2015). Accordingly, it became crucial to identify the actions needed to manage and enhance this urban growth, aspiring to achieve a compact city growth model giving priority to green area developments and landscape fragmentation. Planners recognized the need for availability of urban green spaces (UGS) and their ratio with built environment as one of the key factors in improving said quality of life. The ensuing master planning and development of the city was a result of an implemented coordination strategy between the private sector and the public government authorities, in the attempt to shape the city as "a place that expresses an economic strategy." This effort to integrate led to unclear boundaries between the public and private sectors, where participants from both sectors became actively involved in the decision-making process for the urban development of the city (AL-Mohannadi and Furlan 2020; Fromherz 2017). Therefore, the network between governmental agencies and practitioners from the industry paved the grounds for fast growth management processes in the form of public-private partnerships.

On similar lines, the results of a study by Nadeem Hashem shows that the majority of administrative zones in Qatar fell well below the adopted public park standards (Hashem 2015). Consequently in 2018, efforts were taken by Municipality to identify vacant parcels of land among high-density built fabric (Central Business District of Doha) and to convert them into public parks in a gesture to meet the global public park standards. While well-intended this effort witnessed drawbacks in the planning process. While urban green spaces ought to be treated as vital nodes of the city forming a green network connected through corridors, the planning approach used by municipal authorities evidently resulted in landscape fragmentation, especially making the green spaces vulnerable to isolation and disconnection from the adjacent built environment. As a result, it now becomes necessary to revisit the situation-to consider how these green urban spaces can be rendered accessible through the urban fabric as well as connected to metropolitan green areas, in turn, forming a network or holistic system interconnecting 
people and places. Therefore, the aim of the current study is to recommend strategies to improve urban green networks and to realize a strong \& dynamic landscape system.

Lack of holistic planning is commonplace in numerous large cities in the world, many of whom face immediate population growth due to transformation of economies. These problems are manifest in accelerated changes of land use to cater to the growing needs of "new" population. In the case of Doha, this scenario has been exacerbated by almost doubled and rapid extension of urbanized areas over the past decade. While providing for immediate infrastructures, urban green spaces were not given high priority compared to other necessities such as housing, industrial developments, and infrastructure developments (Furlan and Al-Mohanndi 2018; Tan et al. 2013). Thus, the planning of parks and green spaces became secondary. Eventually, the vacant plots between compact developments were regenerated as green pockets. However, as void and disconnected urban spaces their success was limited. To facilitate more efficient use of these green pockets there must be greater accessibility to/from public destinations and better connections through corridors, thereby counteracting landscape fragmentation (Furlan et al. 2018).

The challenges of landscape fragmentation will be addressed in this study by representing a methodological framework (using graph theory) to assess the "green network" in Doha, considering MIA Park as one of the network's vital nodes. The Museum of Islamic Arts (MIA) Park, opened to the public in 2008 under the authority of Qatar National Museums (QNM), is selected as the case study for this investigation, due to its strategic core location between the sea (water mass) and the dense historical city fabric (land mass), and due to its vibrant and significant physical setting. The study aims at investigating issues and challenges related to the park's "green network" referred as green landscapes (public and private) that form a key part of the built environment. The green network is mapped along the basis of graph theory, which is considered an efficient approach to understand spatial distribution of landscape. The investigation is performed at two scales: (1) neighborhood scale, and (2) city scale, in order to identify the green nodes/edges and the gaps that are fragmenting them. Thus, as a contribution to enhance the green network planning and to reduce green landscape fragmentation, the study develops a spatial model for a more robust, resilient, and effective urban green network.

\section{The research design (data and methods)}

This study aims to assess the existing conditions of MIA Park and to recommend sound strategies for promoting its integration into the surrounding urban fabric. The assessment is conducted through a green network analysis based on the branch of mathematics called graph theory, which is recognized as an efficient way of exploring and assessing spatial/ territorial limits and constraints. In graph theory, one investigates sets of objects called "nodes" (or "vertices"), connected by "links" (also called "lines" or "edges"). The spatial analysis utilizing primary graphs datasets (maps) allows to understand the attributes (and gaps) of the spatial network. The empirical study is defined a cutting-edge inquiry, aiming at defining a new type of spatial network to unfold segments of spatial nodes, which organize and structure social systems. Key concepts and definitions from graph theory are reviewed and utilized to develop a variety of visual maps, which in turn can be utilized to investigated the local (neighborhood-scale) and global (city-scale) network structure (Jona 2018; Secchi 2007; Tadi et al. 2017; Wang and Gonzalez 2009). 
In the present context, nodes are significant places of activity in the city such as transport hubs or public areas like parks, and the links that join them are walkways, bike paths, or roads. An important node without sufficient links connecting it to other nodes represents an inefficiency (e.g., an attractive green space surrounded by busy streets that cannot be safely accessed on foot or by bicycle). Graph theory permits such situations to be analyzed mathematically, though in this paper such findings are summarized qualitatively. Finally, as a contribution to reducing metropolitan landscape fragmentation, the study seeks to promote higher living standards through a green network system planned at the city-scale level. The research design consists of three stages (see Fig. 4) (Denzin and Lincoln 2011; Marshall and Rossman 2014) (Fig. 4).

\section{(1) Theoretical study (literature review)}

The review of the literature involved gathering information about significant planning concepts, such as the role of urban spaces as vital nodes through the urban fabric, the prevalence of green networks' issues and challenges in both international and regional contexts. Citation analysis was used to review the core literature [journals, authors, source places] guided by the following objectives (Denzin and Lincoln 2011; Marshall and Rossman 2014):

- To understand the importance of urban green networks and related challenges from global and regional perspectives;

- To understand the urban growth of Doha city, namely in the context of metropolitan green urban areas and networks;

- To explore the significance of accessibility and connectivity to urban space development, associating it with the goal for planning metropolitan green networks.

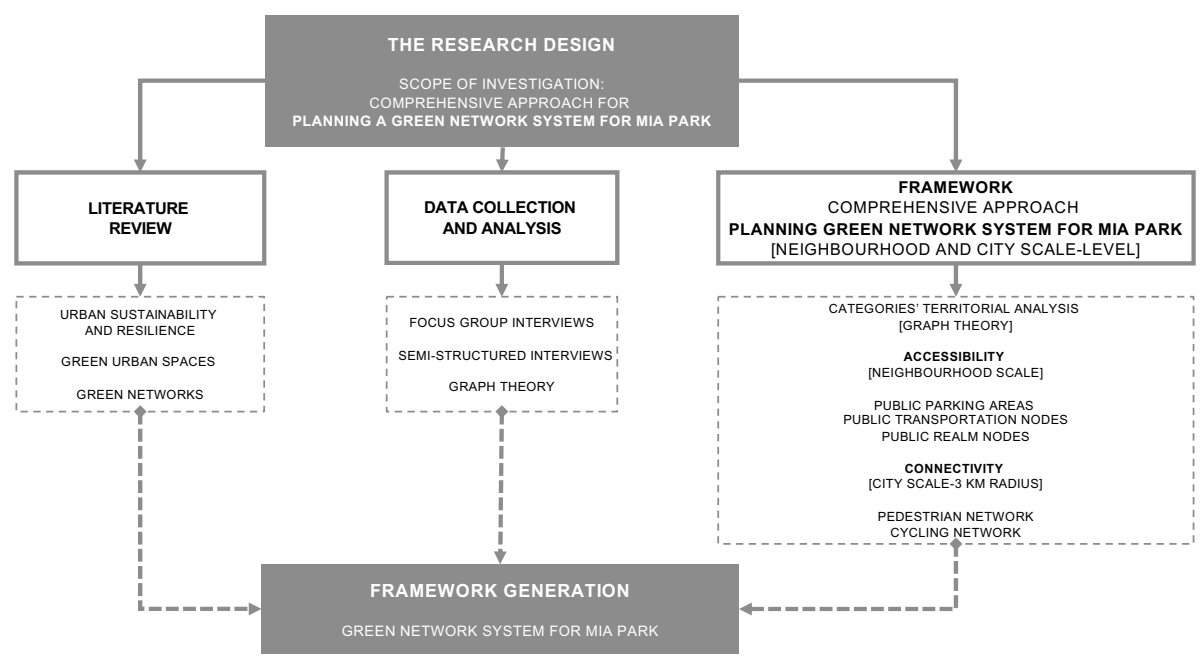

Fig. 4 The research design. Source: The Authors 
(2) Data collection and site analysis

The research study adopts mixed qualitative and quantitative methodology (Creswell 1994). In turn, this approach will allow the researchers to carry out structured interviews and surveys with the participants (i.e., urban designers, planners and city dwellers), with the objective to understand perspectives and individual views about the extent to which a comprehensive approach for planning a green network system for MIA Park in Doha can be implemented at different scales (neighborhood and city-scale levels).

\section{A Data collection-focus group interviews}

Ten focus groups interviews [i.e., 6 members per group] were conducted with 60 participants [e.g., urban and transport planners, urban designers, practitioners, and academics] working for private and public bodies, occupying critical roles in relevant organizations, with expertise in policy analysis on public transport and integration of land use at various scale [local, regional, national] (Newman 2007). The purpose of the focus group interviews was as follows:

- To define the specifics of the geographical context of Qatar and the strategies supporting a planning green network for MIA Park in Doha;

- To aid the identification of design and other barriers related to the adopted strategies for planning the green network system;

- To obtain in-depth insights about Doha master planning and its future challenges to planning practices, community development and city building.

(Appendix A includes copy of the questionnaire and results from the focus group interviews).

\section{B Data collection-semi-structured interviews}

Specifically, in November 2019, oral data were collected through initial questionnaires and semi-structured interviews conducted with 40 professionals and researchers from MME, QR, Ashghal, ASTHAD, Qatar Transportation and Traffic Safety Center [QTTSCQatar University], as well as leading international consultants and research centers working at different geographic scale urban developments in Qatar, and with 60 users, regularly visiting each Park. The purpose of the interviews was as follows:

- To define in detail the visual categories or Layer-Maps [(1) accessibility to/from public parking areas; (2) accessibility to/from public transportation nodes; (3) accessibility to/ from urban green spaces; (4-5) pedestrian and bikes connectivity to/from neighboring urban green spaces] to be explored in order to assess the extent to which green networks for MIA Park can be planned and/or implemented.

- To explore the benefits of planning a green network system for MIA Parks, increasing cycling, walking, and city dwellers' quality of life;

- To investigate governance knowledge barriers and obstacles hampering the development of green networks in practice, in order to implement more potent urbanization process and/or compelling master planning in Qatar. 
(Appendix B includes copy of the questionnaire and results from the semi-structured interviews).

\section{C Data collection-visual material}

The methods adopted for collecting visual data were site visits and observations, cartographic maps, aerial views and photographs. A network analysis based on graph theory provided a way of framing and evaluating features of mobility to and around the selected case study green urban space and to identify gaps related to accessibility and connectivity at the required neighborhood and city-scale levels. The graph comprised a network represented through graph-drawings of nodes $(\mathrm{N})$ and corridors $(\mathrm{C})$, where the node $(\mathrm{N})$ represents a habitat (Fucile et al. 2017).

\section{D Site analysis}

The network analysis of the collected data allowed the research team to define a comprehensive approach for planning a green network system for MIA Park, integrating alternative circulation systems at both scale levels, based on the assessment tools (1) accessibility [green network from/to urban green space to/from neighboring districts], and (2) connectivity [green network from/to urban green space to/from neighboring urban green spaces].

(3) Findings: planning the neighborhood and city-scale level green network system for MIA Park

Research by design is a commonly applied methodology in urbanism and architecture encompassing two steps: (1) territorial analysis of the investigated area, and (2) generation of a vision, as a way to produce concrete ideas of the investigated area's metamorphosis, through specific design tools. Particular emphasis is given to the interplay between territorial analysis (network analysis based on graph theory) and design exploration (Proposal for a Masterplan). The resulting approach for planning a green network system for MIA Park summarizes the framework enhancing the dependency between mapping and design. As a result, the proposed urban design and planning guidelines (i.e., recommendations) are based on addressing and filling the gaps highlighted through the two territorial analyzed design tools of investigation, (1) accessibility, and (2) connectivity. The systematic "research-bydesign" approach consists of reading and comprehending possible interdependencies and unlocking potentials between flows at two different urban design and planning scale: (1) Neighborhood, and (2) City levels (Benevolo 1967; Secchi 2005; Tadi et al. 2017).

\subsection{Case study setting}

\subsubsection{MIA Park}

MIA (Museum of Islamic Arts) Park, marking the skyline of Doha, surrounds the Museum of Islamic Arts, which is located in Doha Port area, adjacent to the Al Salata and Al Souq areas. The park is directly connected to the Corniche and Doha Port, which makes it the starting point of the longest walkway for pedestrians in Doha: The Corniche. It is also significantly 

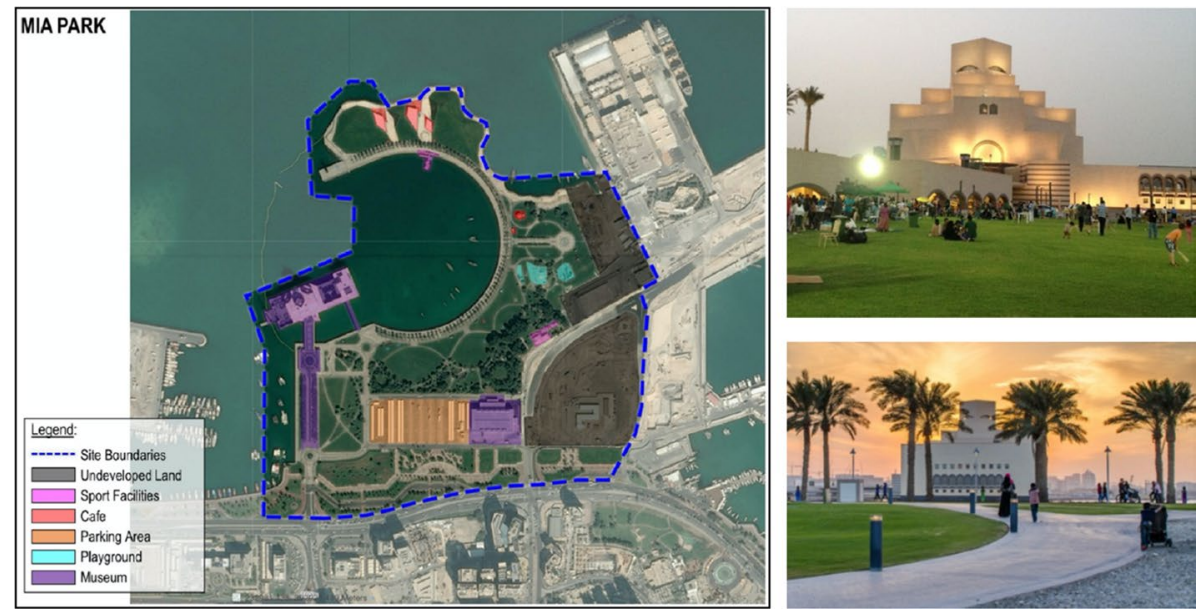

Fig. 5 MIA Park in Doha. Source: The Authors

located nearby the Souq Waqif and Qatar National Museum. The park has a crescent-like shape around the Museum of Islamic Arts and is directly linked to the Corniche (Fig. 5).

MIA Park, officially opened to the public in 2011, was developed by Qatar Museums Authority (QMA) and was designed by Pei Partnership Architects from New York. It was developed to be a new cultural destination on Doha's Corniche. According to QMA, the vision to develop MIA was to encourage global cultural exchange and introduce the Qatari community to global art and culture. Therefore, the crescent design of the park's walkway features a vertical steel sculpture by the famous American artist Richard Serra in one attempt to showcase said global art and culture.

The MIA Park was planned with the vision to complete the museum through establishing a dynamic place for cultural exchange and creative learning and exploration for children, families and art enthusiasts, with recreational activities designed to attract the majority of community. Also, the area is considered to be an attraction for picnics and social gatherings of friends and families, especially on weekends, as well as serving as a retail spots hosting various festivals during the cooler months of the year in Qatar (MIA Bazaar).

\section{Results}

The findings are structured into two sections: (1) Site analysis (or territorial analysis based on graph theory) and (2) MIA Masterplan Proposal and Guidelines. The site analysis, assessed and developed as per two assessment tools, (1) Accessibility and (2) Connectivity provided the insights for the development of the ensuing masterplan and guidelines, based on a comprehensive approach for implementing a spatial model of urban green network, aiming at reducing landscape fragmentation in Doha (Secchi 2007).

\subsection{Site analysis}

The site analysis is conducted based on the assessment of two aspects: 
1. Accessibility to/from neighboring districts (neighborhood-scale level):

- Public parking areas (private vehicle use);

- Public transportation nodes (pedestrian and cyclist network);

- Public realm nodes (pedestrian and cyclist network).

2. Connectivity to/from neighboring urban green spaces (city-scale level):

- Pedestrian network within a $3 \mathrm{~km}$ radius from MIA Park;

- Cycling network within a $3 \mathrm{~km}$ radius from MIA Park.

\subsubsection{Accessibility to/from public parking areas}

There are two public car parking areas available at MIA Park (Fig. 6a). The first car parking area, located to the eastern side of the entrance gate of MIA, is dedicated only to MIA visitors. The second car parking area, located along the Corniche promenade, while less restricted can be used by MIA visitors.

The MIA car parking area can accommodate up to 500 cars at once. According to observations, this parking area can be fully occupied during weekends. However, as this parking area is common for both the museum and park visitors, it can be slightly congested especially in the case of events taking place at the museum. The car parking area along the Corniche promenade can be used by the MIA park visitors, but does not serve as its main parking area. This parking area is occupied most of the time by the Corniche visitors. Therefore, traffic congestion could occur if large number of visitors are visiting the park.

One of the prime factors to achieve sustainable urbanism principles, is to reduce the need to use private cars in order to reach MIA Park. This can be achieved through
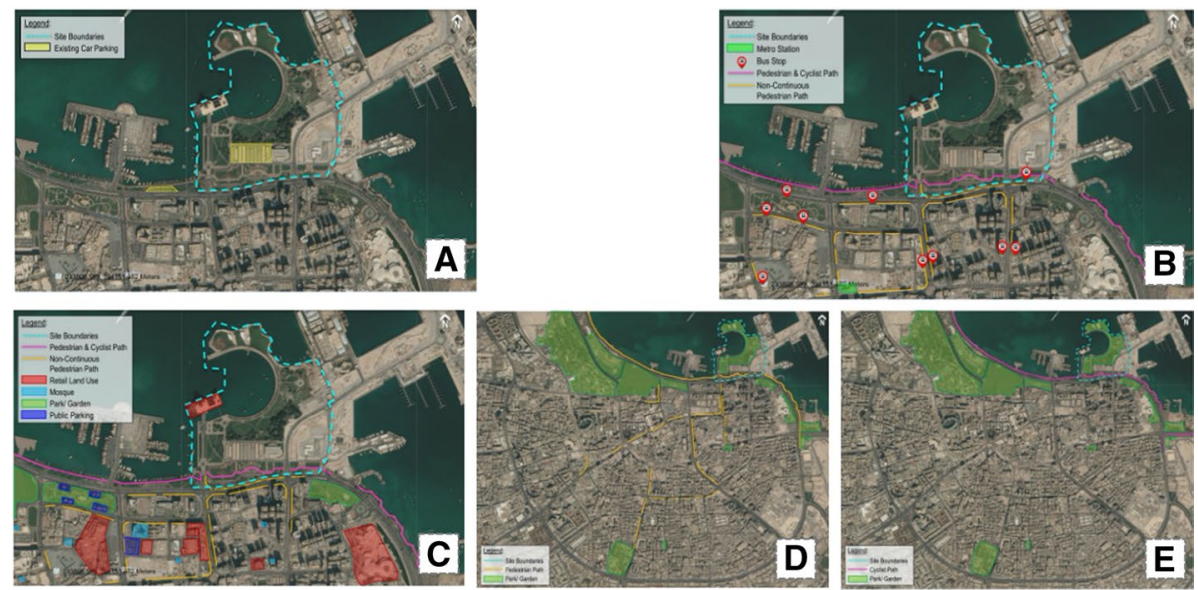

Fig. 6 Site analysis. a Accessibility: Existing car parking for MIA Park; b Accessibility: Non-continuous pedestrian path from the metro station in Souq Waqif and various bus stops in the neighborhood to the MIA park; c Accessibility: Non-continuous pedestrian path from public destinations to the MIA park; d Connectivity: Existing pedestrian network around MIA park showing the non-continuous connection between urban green spaces in Doha Metropolitan area; e Connectivity: Existing cyclist network around MIA park in Doha Metropolitan area. Source: The Authors 
designing efficient pedestrian pathways and cyclist networks around and beyond MIA Park. The recommended design and policy framework are developed to promote a continuous pedestrian network, for example connecting nearby parking areas to MIA Park.

\subsubsection{Accessibility to/from public transportation nodes}

There are two modes of public transportation in Doha: city buses and the new Doha metro. The nearest metro station for MIA Park is Souq Waqif metro station, which is about one kilometer away. Also, within the one kilometer distance, there are about six bus stops, out of which three stops are located along Al Corniche Street which lead directly to the MIA Park (Fig. 6b).

Until December 2019, the only mode of public transportation in Doha was city buses, which was not sufficient and hence, the use of cars proved dominant. In fact, the opening of Doha metro has increased the number of MIA Park visitors, especially during the weekends. Therefore, it can be highlighted that considering and prioritizing pedestrian accessibility from the metro station to the MIA Park will guarantee safe and easy access for visitors. Moreover, the location of bus stops along the path between the metro station and MIA Park can further aid in creating this network for pedestrian and cyclist accessibility. Therefore, the present non-continuous pedestrian path shall be re-planned and developed into a more accessible, efficient and continuous network.

From the analysis, it can be concluded that there is no convenient accessibility from public transportation nodes directly to the MIA Park. Namely, the lack of efficient and continuous pedestrian network from Souq Waqif metro station and bus stops result in lack of accessibility to the MIA Park. The pedestrian path is non-continuous, mainly due to building boundaries and lack of sidewalks, which are damaged and/or missing most of the time. Therefore, the walking experience to the MIA Park is uncomfortable and unsafe due to the recurring and conflicting vehicular movement. Additionally, the harsh climate of Doha is during summer makes it difficult for pedestrians to walk without shading devices. The lack of urban design elements, such as sidewalks, vegetation buffer, water features, shading, and seating at reasonable and regular intervals, makes the existing pedestrian network inefficient.

\subsubsection{Accessibility to/from public realm nodes}

There is a wide variety of existing public destinations around the MIA Park. Retail places, religious institutions, plazas, and parks are all examples of public realm nodes (Fig. 6c). Al Bidda Park and Qatar National Museum which are about $800 \mathrm{~m}$ away from the MIA Park are significant destinations with similar land use. Primarily, there are three public nodes that can be listed near the MIA Park: (1) Al Bidda Park, (2) Qatar National Museum, and (3) Souq Waqif. All of these prominent civic amenities lack convenient and safe accessibility for pedestrians and cyclists alike.

There is an absence of a well-planned pedestrian and cyclist network connecting the MIA Park with nearby public destinations. The existing pedestrian path is not implemented with the idea to create an accessible and well-connected network. In fact, the pedestrian path is provided for each building and public place independently without a holistic consideration of realizing a contiguous, safe and comfortable pedestrian network. According to international urban design standards, pedestrian networks should be continuous, safe, 
comfortable, permeable, accessible, and possess urban design elements that enhance user satisfaction and friendliness. Currently, none of the standards are being implemented in the neighborhood of the MIA Park. In the case of Corniche promenade, although that the pedestrian path is continuous, it is still isolated from key public realm nodes.

It can be argued that a well-planned pedestrian and cyclist network should be implemented to provide safe and convenient access to the MIA Park from the nearby public realm nodes. The network should be linked to the Corniche promenade to ensure holistic and seamless accessibility. A possible suggestion would be to provide pedestrian bridges at crossings and intersections to ensure continuous traffic flow and safe pedestrian movement.

\subsubsection{Connectivity to/from neighboring urban green spaces (pedestrian network)}

Connectivity here refers to the pedestrian and cyclist network between the parks in Doha Metropolitan region. The first step in strengthening and improving the city-wide system involves mapping of all the regional, local and all smaller public parks which can be used by all citizens. From the map (Fig. 6d), it can be observed that the spatial distribution of green space is fragmented and there is absolutely no connection between the parks, which makes them inefficient in use as well.

Cities around the world are prioritizing "smart connectivity" as one of the primary urban planning elements. Smart connectivity not only involves sustainable transportation options but also includes non-motorized connectivity by providing for safe and comfortable pedestrian and bicycle networks. The map in Fig. 6 marks the current pedestrian condition in context of urban green spaces in the city.

Kevin Lynch (K. Lynch 1981) in his book "A Theory of Good City Form" examined the benefits of open space networks, which should be accessible from the urban fabric of the city, in order to reduce motorized vehicular movements. Similarly, in the case of MIA Park precinct, the road network is the only network connecting places and blocks. Hence, it is argued that (1) the green network (pedestrian and bicycle) should be planned along with the current road connectivity and (2) should form a new network (cutting through blocks) overlaying the fabric in a way that doesn't disturb the existing road network.

\subsubsection{Connectivity to/from neighboring urban green spaces (cyclist network)}

While there are two larger parks adjacent to the ring roads, all the smaller parks are far from the main roads. MIA Parks connection to Al Bidda park is defined by the Corniche street and hence, the two regional parks are well-connected through a bicycle network. The network does not connect to smaller parks (Fig. 6e). As most of the parks in the city were planned on the unused vacant plots, their locations were obviously not strategically planned. That said, the researchers contend that redesigning and retrofitting the city's urban space system could link many of the landscape spaces into a more successful, ecological and attractive green space network.

The territorial analysis highlights the lack of a bicycle network within the metropolitan area. The only bicycle pathway present is along the Corniche Street which connects the two regional parks (MIA Park and Al Bidda Park). The rest of the urban green spaces lack any bicycle network. Multi-modal transit options are critical to moving forward in efforts to heighten livability and sustainability in Doha. 

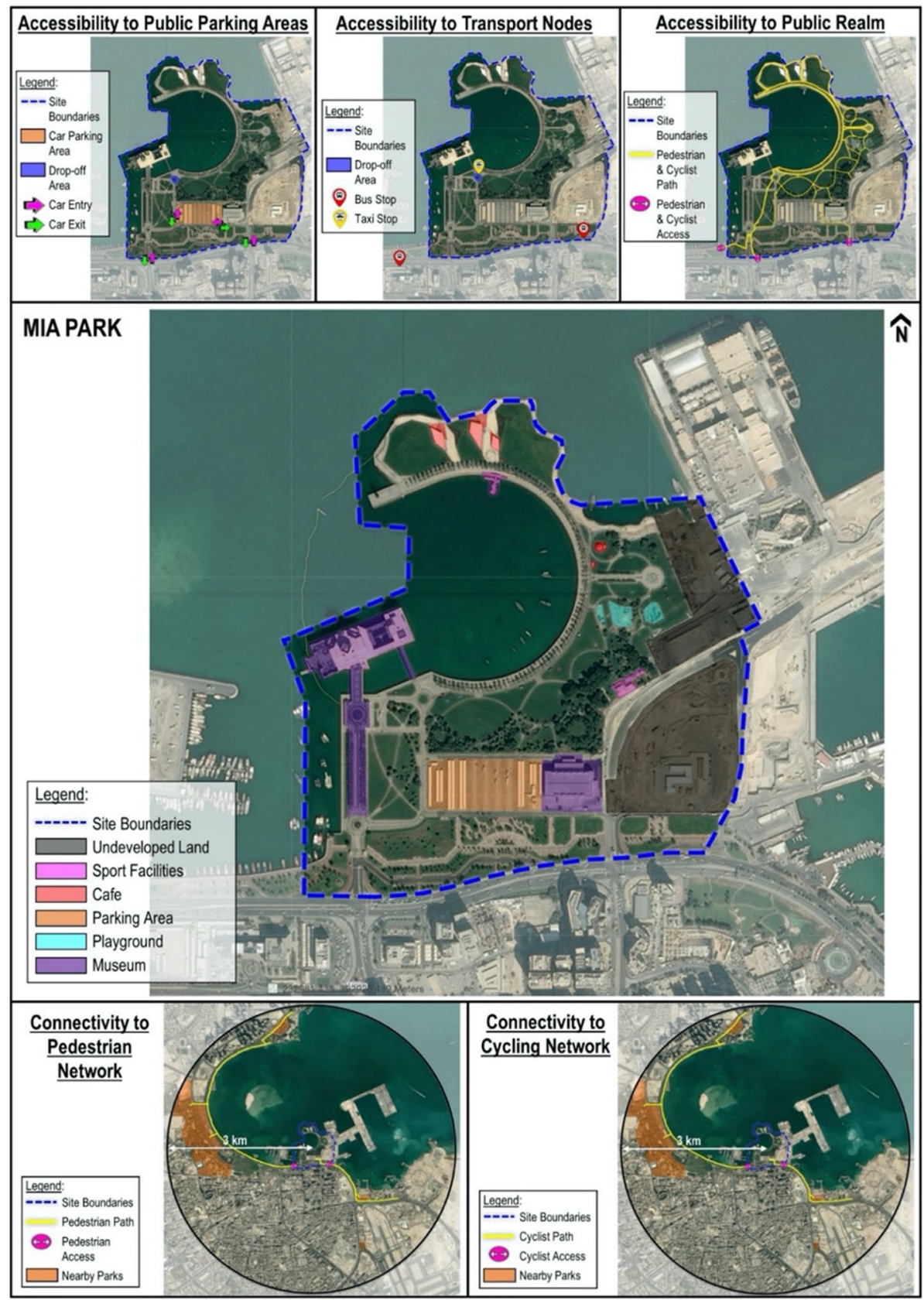

Fig. 7 MIA Park Territorial (network) analysis based on graph theory. Source: The Authors 


\subsection{Masterplan and guidelines}

MIA Masterplan and Guidelines summarize the framework enhancing the dependency between mapping and design. As a result, the proposed Masterplan (Urban Design) and extracted guidelines (Urban Planning) are based on addressing and filling the gaps highlighted through the territorial analyzed design tools of investigation (Fig. 7).

\subsubsection{Accessibility from public parking areas}

The proposal places livability front and center, and to these ends, promotes walkability and the concept of "putting cars in their place." Assigning cars to appropriate spaces is essential for shaping Doha as a more pedestrian-friendly city. While the current arrangement of car parks is sufficient, there is a need to improve the walkability from these parking areas (Fig. 8a) to the surrounding communities, amenities and destinations. To ensure comfortable and safe walking from the parking areas, some design actions are required (1) to safe guard existing parking facilities and enhance them with appropriate urban design elements, such as, 24/7 surveillance and proper shading provisions, (2) to allocate bridges overpasses (at every $100 \mathrm{~m}$ ) connecting Al Bidda Parking to the pedestrian network of the Corniche waterfront, and (3) to enact parking fees for the parking facility to encourage city dwellers to use public transportation and discourage reliance on private cars.

\subsubsection{Accessibility from public transportation node metro stations}

There is complete lack of a cohesive pedestrian and bicycle network between MIA Park and the public transportation nodes metro stations. The researchers contend that corridors
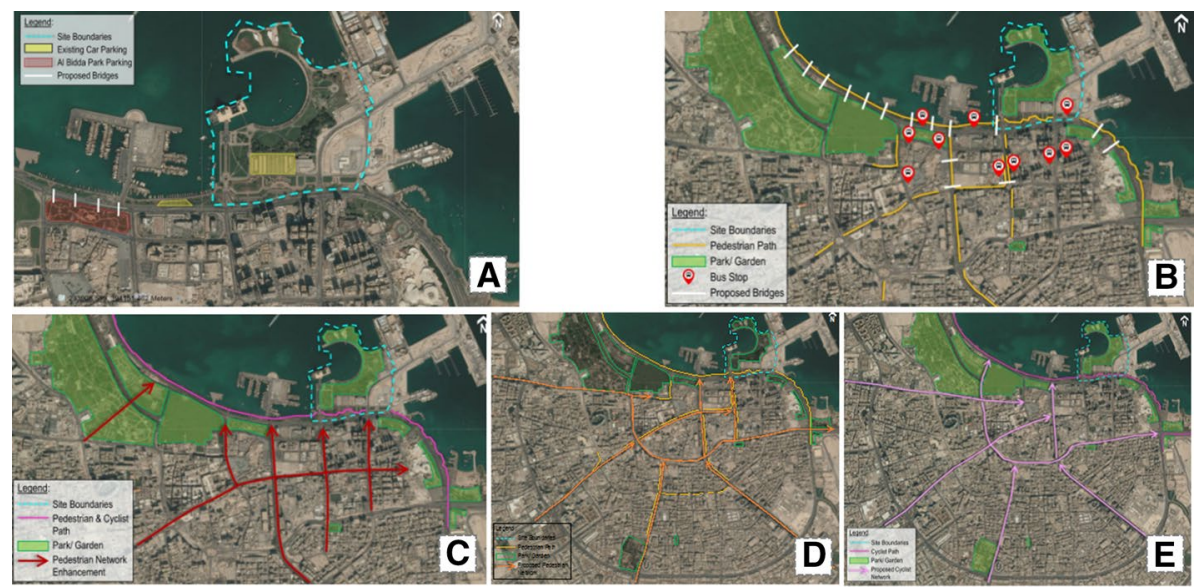

Fig. 8 Proposed Masterplan. a Bridges (at every $100 \mathrm{~m}$ ) connecting Al Bidda Park Parking to the pedestrian network around MIA Park; b Green network connecting public transportation nodes to MIA Park and proposed bridges (at every $100 \mathrm{~m}$ ) connecting Al Bidda Parking to the pedestrian network; $\mathbf{c}$ Interconnected green network (includes pedestrian and bicycle path) and proposed enhancement of Corniche pedestrian by installing element for safety and comfort; $\mathbf{d}$ Interconnected green network (includes pedestrian and bicycle path) and proposed enhancement of Corniche pedestrian by installing element for safety and comfort; e Proposed cyclist network at city scale. Source: The Authors 
and connections are vital ingredients to a more livable city and to a more successful urban space network. The proposed network recommends connecting the neighboring urban fabric to MIA Park through a well-designed pedestrian and bicycle network. While the Corniche Street has a well-used and well-developed pedestrian network all the way across the Corniche curve, the main challenge will be to connect users from the other side of this arterial road and/or to provide sun-shaded bridges at every $200 \mathrm{~m}$ for people to cross the arterial road (Al Corniche Street) in a safe and comfortable manner. Urban design and open space intervention should aim to seamlessly weave together pedestrians, bikes, parks, nodes, and amenities into an attractive and accessible public realm (Fig. 8b).

\subsubsection{Accessibility from public realm nodes pedestrian/cycling network}

The proposed network would ensure permeability from all the roads connecting public realm nodes in the neighborhoods nearby MIA Park (Fig. 8c). Currently, the bicycle network that presently runs only along the Corniche, will need to be connected to the proposed bicycle network along the proposed pedestrian network, to ensure safety and comfort. Such intervention should incorporate (1) safe and frequent pedestrian crossings and bridge overpasses (for pedestrians and bikers alike), thereby providing for easy connection across the road, and (2) the installation of shaded seating, small planters, landscape, waste bins along the pedestrian and bicycle pathway, which would ensure a safe and comfortable experience for visitors and city dwellers.

\subsubsection{Connectivity to/from neighboring urban green spaces (pedestrian network)}

A continuous pedestrian network from all the major ring roads should be planned at the neighborhood scale (Fig. 8d). (1) Preferencing walking over an automobile commute can be facilitated by enhancing community activities, informal vendor, and food trucks along the network; (2) Signboards, lighting, and other urban design elements would also encourage walking and/or multi-modal integrative participatory approaches;

\subsubsection{Connectivity to/from neighboring urban green spaces (cycling network)}

A continuous cycling network from all the major ring roads should be planned at the neighborhood scale (Fig. 8e). Such a strategy must consider that (1) cycling could be encouraged through the provision of bikes lanes, designed with anti-skid pavement and sufficient lighting (especially during the dark hours) to ensure safe travel and access for the bikers; (2) where it is required to make provision for road crossing and intersections, bikers should be given priority over motorized vehicles; (3) Street furniture and resting spaces-nodes at regular intervals should be provided to provide comfortability to bikers, and (4) the potential for bike-share and other programs that encourage easy use of bicycles as a viable alternative to automobiles. 


\section{Conclusion and discussion: a green network for Mia Park with ecological and social functions}

City planning and design is complex, and is becoming more so as the world grapples with concerns around livability and sustainability (Molotch and Ponzini 2019; Saliba 2015). The insights revealed through a network analysis investigation, based on graph theory, allowed the researchers to define a specific novel approach to enhance (1) accessibility, and (2) connectivity of MIA Park. While accessibility from from/to neighboring districts was assessed from (a) public parking areas (private vehicle use), (b) Public transportation node metro station (Pedestrian and Cycling Network); (c) public realm (Pedestrian and Cycling Network), connectivity was assessed from/to neighboring urban green spaces/public realm located within $3000 \mathrm{Mt}$ radius, as maximum walkable distance for a healthy adult, through (d) Pedestrian Network, and (e) Cycling Network. While these parameters are noted individually, the research team underscores the crucial demand to approach design using the framework in a holistic and systemic manner.

This research study confirmed that graph theory is an effective method for providing recommendations for the green network system of parks, based on (1) the neighborhoodscale and (2) the city-scale levels. One of the major issues for an effective network is related to the selection, assessment and strategic linking of nodes and corridors along the territory. Nodes, or greener, outdoor neighborhood hubs where people and nature meet for recreation, resting, community events, must be meaningfully and seamlessly connected to one another by corridors. Nodes are categorized as follow:

- Built-up nodes provide small open areas for recreation supporting the neighborhood social-spatial fabric, through playground, public art, or space for community events;

- Nature nodes provide small green open areas as habitat for wildlife moving across the city, keeping spatial ecosystems cooler, shadier healthy;

- Institution nodes provide large natural-green areas (i.e., parks) and built-up areas (i.e., town squares) to be utilized for community recreation, social gatherings, relief, health, and wellness.

Nodes must be connected through corridors, commonly green-linear lanes that provide shade and cooling as well as accommodating safe, comfortable movement within neighborhoods and/or through the urban fabric. Corridors are categorized as follow:

- Built-up corridors creating safe movement for city dwellers who walk or bike through the nodes, include trees, median plantings, improved sidewalks, protected bikeways.

- Nature Corridors are the semi-intact natural areas in the city, providing habitat for important native wildlife and a healthy environment for city dwellers.

- Parkway vehicular corridors include parkways and boulevards, as well as streets, aligning with historic streams. 


\section{Implication of practice and advancement of research}

The present research, while considering the singular case of MIA Park, highlights that the principles of green networks and ecological urban design extend to other cities in the region and well beyond. The proposed framework for neighborhood and city-scale green network system planning for the MIA Park highlights the extent to which an urban planning approach needs to be implemented to enhance accessibility and connectivity of MIA Park to/from neighboring districts and urban green areas, through two-scale level method. Furthermore, the insights from this study stress that the amount of green spaces and their spatial distribution within the metropolitan limits of the city are insufficient to reduce arguably endemic landscape fragmentation. In order to reduce this gap, the urban planning of green areas requires a far more comprehensive and holistic approach, based on enhancing concurrently the ecological, social and connectivity systems, and considering their interrelationships integration in further detail. Ecological diversity, landscape connectivity, and recreational values (often related to social-cultural aspects) should be emphasized and addressed as measurable tools to envision and foster such green areas-urban development approaches. Functionality of landscape connectivity is achieved through the spatial configuration of urban elements such as patches (open spaces and/or public realm) and corridors (pedestrian and cycling network): such spatial configuration (the green areas' network) has to be investigated and planned by urban planners, while spatial ecological diversity has to be explored and planned by landscape urban designers and/or architects, and social-spatial activities have to be explored and planned by urban sociologists and/or social scientists. The researchers argue an interdisciplinary inter-sector strategy must be developed when translating our framework from theory to practice - the planning, design and building of more livable and sustainable cities is a daunting yet urgent task.

During the last six or seven years a new field of study has developed, concerned with interdisciplinary study of the mutual interaction of people and their built environments. Scholars and professionals from a number of disciplines - architecture, planning, psychology, sociology, social psychology, geography, ethology, psychiatry, and so on-have begun to address questions about how environments have been shaped and how they should be designed, what effects environments have on people and what are the important mechanism linking people and environments (Rapoport 1976, p. ix).

As argued by Rapoport, the collaboration of multi-disciplinary consultants, such as designers, architects, urban and transport planners, sociologists, psychologists, and other social scientists will provide key insights constituting the foundation knowledge for the implementation of the city masterplan, with the ultimate goal of implementing livability and well-being of any urban settlement. Furthermore, as highlighted by the findings revealed from this investigation, Qatar has several challenges in shifting from a car-based culture and automobile-driven spatial environment toward a more sustainable walkable humanscaled city. Therefore, it is crucial to plan for the implementation of the masterplan, where within the city (and its districts), streets (serving as corridors) and green areas (serving as nodes) are interconnected, through ecological and social functions-coming together (like the human body) as a living organism, not just through the use of private vehicles and/or public transport systems, but through well-considered, well-designed, enjoyable and effective pedestrian and cycling networks. This vision and approach to urban planning would provide a rich opportunity for reshaping urban planning policies, guidelines and strategies 
for the development of a master plan aiming at reducing the currently isolated and/or fragmented landscape within metropolitan Doha. While the present paper has critically considered the unique case of Doha Qatar, the authors contend that many of the environmental design strategies delineated are relevant to cities in the gulf Region, and in numerous aspects, are applicable well beyond.

Further studies about a contextualized placemaking-approach for different/multiple green urban areas in the State of Qatar should be explored and investigated at regional (macro-scale), metropolitan (civic-scale) and neighborhood (micro-scale) levels. A multiscalar placemaking-approach would allow city makers to better customize the proposed framework for comprehensively integrating built and natural environments through a wellconceived green network system. Further investigation about the functional-spatial roles of different types of green nodes and corridors in Qatar would provide the required and valuable insights for generating a more-detailed and implementable framework, which would go beyond being optional features to locally improve environments but rather promises to serve as a valuable model for the sustainable master planning of Doha, future cities in the State, and in cities across the GCC. In light if pressing demands to heighten the health and wellness of city dwellers, the crafting of such a framework comprises a key research objective for the research team moving forward.

Acknowledgements The authors would like to acknowledge the research-oriented vision of Qatar University as an academic institute supporting sustainable development in the State of Qatar. This research study was developed as part of two research project schemes: (1) Collaborative Grant QUCG-CENG-1920-4 titled "The Action Plan for the Implementation of Qatar National Masterplan based on Integration of Land Use and Public Transport Systems", awarded and funded by Qatar University; (2) UREP 23-065-5-001 titled "Sustainable Urbanism for the Urban Regeneration and Preservation of the Cultural-Heritage Site of the Souq Waqif in Doha (State of Qatar)", awarded and funded from Qatar National Research Fund (QNRF, a member of Qatar Foundation).

The authors would like to express their gratitude to the leading planners and architects of Qatar's Government Agencies and Ministries, namely the Ministry of Municipality and Environment (MME), Qatar Rail (QR), Qatar Museums Authority (QMNA) and Ashghal Public Works Authority for their collaboration, for participating in the meetings, sharing visual data and cardinal documents relevant to the research aims, and for discussing the results and conclusion of this investigation.

This paper was subject to a Double-Blind Peer Review process. Once accepted for publication, the journal 'Environment, Development and Sustainability (ENVI)' offered the authors the choice to publish this article on open access (OA). The open access (OA) funding were provided by the Qatar National Library. Finally, the authors thank the anonymous reviewers for their comments, which contributed to an improvement of this paper. The authors are solely responsible for the statements made herein.

Funding Open Access funding enabled and organized by projekt DEAL.

Open Access This article is licensed under a Creative Commons Attribution 4.0 International License, which permits use, sharing, adaptation, distribution and reproduction in any medium or format, as long as you give appropriate credit to the original author(s) and the source, provide a link to the Creative Commons licence, and indicate if changes were made. The images or other third party material in this article are included in the article's Creative Commons licence, unless indicated otherwise in a credit line to the material. If material is not included in the article's Creative Commons licence and your intended use is not permitted by statutory regulation or exceeds the permitted use, you will need to obtain permission directly from the copyright holder. To view a copy of this licence, visit http://creativecommons.org/licenses/by/4.0/. 


\section{References}

Artmann, M., Bastian, O., \& Grunewald, K. (2017). Using the concepts of green infrastructure and ecosystem services to specify Leitbilder for compact and green cities-the example of the landscape plan of Dresden (Germany). Sustainability, 9(2), 198. https://doi.org/10.3390/su9020198.

AL-Mohannadi, A., \& Furlan, R. (2020). The syntax of the Qatari traditional house: The spatial effect of privacy, gender segregation and hospitality. Journal of Asian Architecture and Building Engineering. https://doi.org/10.1080/13467581.2020.1869555.

AL-Mohannadi, A., Furlan, R., \& Major, M. D. (2020). A cultural heritage framework for preserving Qatari vernacular residential srchitecture. Sustainability, 12(18), 7295. https://doi.org/10.3390/su12187295.

Bacon, E. N. (1967). Design of cities. New York: The MIT Press.

Beatley, T. (2000). Green urbanism, learning from European cities. Washington: Island Press.

Beatley, T., \& Newman, P. (2009). Green urbanism down under-learning from sustainable communities in Australia. Washington: Island Press.

Bell, S. D., Graham, H., \& White, P. C. L. (2018). The role of managed natural spaces in connecting people with urban nature: a comparison of local user, researcher, and provider views. Urban Ecosystems, 21, $875-886$.

Benevolo, L. (1967). The origins of modern town planning. London: Routledge and Kegan Paul.

Black, C. (2016). Urban Green Spaces. Health and Urban Sustainability. http://www.euro.who.int/_data/asset s/pdf_file/0005/321971/Urban-green-spaces-and-health-review-evidence.pdf?ua=1.

Creswell, J. (1994). Research design: Qualitative and quantitative approaches. Thousand Oaks: Sage Publications.

Denzin, N. K., \& Lincoln, Y. S. (2011). The Sage handbook of qualitative research. London: Sage Publications.

Elsheshtawy, Y. (2008). The evolving Arab City: Tradition, modernity \& urban development. New York: Rouledge.

Ericson, D. (2012). MetroGreen: Connecting open spaces in North American Cities. Michigan, USA: Island Press.

Ezzeddine, I., \& Kashwani, G. (2019). Public squares in UAE sustainable urbanism: Social interaction \& vibrant environment. Architecture Research, 9(2), 23-32. https://doi.org/10.5923/j.arch.20190902.01.

Fromherz, A. J. (2017). Qatar-rise to power and influence. London: I.B Tauris \& Co., Ltd.

Fucile, R., Figlia, L. D., Pisano, C., Lucchesi, F., Lingua, V., \& Luca, G. D. (2017). Telling the future: Spatial concepts and methaphors in the represenation of strategis visions. Urbanistica, 160, 88-90.

Furlan, R. (2019). Qatar, Doha. In P. D. J. Corcoran, N. Sipe, I. Mateo-Babiano, \& D. Stead (Eds.), Parking: An international perspective. UK: Elsevier.

Furlan, R., \& Al-Mohannadi, A. (2018). The practice of city planning and design in the Gulf region: The case of Abu Dhabi, Doha and Manama. International Journal of Architectural Research-ArchNetIJAR, 12(2), 126-145.

Furlan, R., \& AL-Mohannadi, A. (2020). The urban regeneration-planning scheme for the Souq Waqif, Heritage site of Doha. Sustainability, 12(19), 7927. https://doi.org/10.3390/su12197927.

Furlan, R., \& Al Thani, S. (2020). An integrated design strategy for the urban regeneration of West Bay, business district of Doha [State of Qatar]. Designs, 4(55), 1-19. https://doi.org/10.3390/designs404 0055 .

Furlan, R., \& Harami, A. (2020). Qatar national museum-transit oriented development: The masterplan for the urban regeneration of a 'Green TOD'. Journal of Urban Management, 9(1), 115-136.

Furlan, R., Petruccioli, A., \& Jamaleddin, M. (2019). The authenticity of place-making: Space and character of the regenerated historic district in Msheireb, Downtown Doha (State of Qatar). International Journal of Architectural Research-ArchNet-IJAR, 13(1), 151-168.

Furlan, R., Petruccioli, A., Major, M., Zaina, S., Saeed, M. A., \& Saleh, D. (2018). The urban regeneration of West-Bay, business district of Doha (State of Qatar): A transit oriented development enhancing livability. Journal of Urban Management, 8(1), 126-144.

Furlan, R., \& Sipe, N. (2017). Light rail transit (LRT) and transit villages in Qatar: A planning-strategy to revitalize the built environment of Doha. Journal of Urban Regeneration and Renewal, 10(4), 1-20.

Furlan, R., Zaina, S., \& Pathel, S. (2020). The urban regeneration's framework for transit villages in Qatar - The case of Al Sadd in Doha. Environment, Development and Sustainability (ENVI). https://doi. org/10.1007/s10668-020-00853-4.

Furlan, R., Zaina, S., \& Zaina, S. (2016). Urban planning in Qatar: Strategies and vision for the development of transit villages in Doha. Australian Planner, 53(4), 286-301.

Galderisi, A., \& Ceudech, A. (2010). Soft mobility and pedestrian networks in urban areas 1. TeMA Journal of Land Use, Mobility and Environment. https://doi.org/10.6092/1970-9870/119.

Gehl, J. (2011). Life between buildings: Using public space. New York: Island Press. 
Gehl, J., \& Svarre, B. (2013). How to study public life. Washington: Island Press.

Gottdiener, M., Hohle, R., \& King, C. (2019). The new urban sociology. New York: Routledge.

Gunay, B. (2003). Design Brief for Doha Corniche: Qatar's Centre for Arts \& Culture. Ankara: Aga Khan Trust for Culture National Council for Arts and Culture. The State of Qatar.

Haas, T. (2012). Sustainable urbanism and beyond-rethinking cities for the future. New York: Rizzoli International Publications.

Hashem, N. (2015). Assessing spatial equality of urban green spaces provision: A case study of Greater Doha in Qatar. Local Environment, 20(30), 386-399.

Jansson, M. (2014). Green space in compact cities: The benefits and values of urban ecosystem services in planning. Nordic Journal of Architectural Research, 2014, 139-160.

Jona, G. (2018). A Hungarian and Ukrainian Competitors' network: A spatial network analysis perspective. Urban Science, 2(4), 99.

Kabisch, N., \& Bosch, M. A. V. D. (2017). Urban green spaces and the potential for health improvement and environmental justice in a changing climate. In N. Kabish, H. Korn, J. Stadler, \& A. Bonn (Eds.), Naturebased solutions to climate change adaptation in urban areas: Theory and practice of urban sustainability transitions. Sringer: Cham.

Kahn, P., Friedman, B., Gill, B., Hagman, J., Severson, R. L., Freier, N. G., \& Stolyar, A. (2008). A plasma display window? - The shifting baseline problem in a technologically mediated natural world. Journal of Environmental Psychology, 28(2), 192-199.

Kostof, S. (1991). The city shaped-urban patterns and meanings through history. London: Thames and Hudson.

Lynch, K. (1960). The image of the city (Vol. 11). USA: MIT press.

Lynch, K. (1981). A theory of good city form. Massachusetts: The MIT Press.

Marshall, C., \& Rossman, G. B. (2014). Designing qualitative research (3rd ed.). California: Sage Publication.

Massicotte, P., \& Frenette, J. J. (2011). Spatial connectivity in a large river system: Resolving the sources and fate of dissolved organic matter. Ecological Applications, 21(7), 2600-2617. https://doi. org/10.2307/41416682.

Mell, I. C. (2017). Green infrastructure: reflections on past, present and future praxis. Landscape Research, 42(2), 135-145.

MME. (2008). Qatar National Vision 2030. General Secretariat for Development.

Molotch, H., \& Ponzini, D. (2019). The new Arab Urban: Guld cities of wealth, ambition, and distress. New York: New York University Press.

Morris, A. E. J. (1979). History of urban form-before the industrial revolutions. New York: John Wiley \& Sons.

Newman, L. (2007). Basics of social research (2nd ed.). Boston: Pearson.

Oliveira, F. L. D. (2017). Green wedge urbanism-history, theory and contemporary practice. London: Bloomsbury Publishing Plc.

Olsson, H. (2012). Integrated Green Spaces in Urban Areas - A case study of inner Brisbane. Master programme in Landscape Architecture. Master Degree, Griffith University, Brisbane, Australia.

Rapoport, A. (1976). The mutual interaction of people and their built environment. Chicago: Aldine Publishing Company.

Roberts, P., Skyes, H., \& Granger, R. (2017). Urban regeneration. London: Sage Publications LtD.

Rossi, A. (1984). The architecture of the City. New York: MIT Press.

Salama, A., \& Wiedman, F. (2013). Demystifying Doha. Farnham, UK: Ashgate Publishing Limited.

Saliba, R. (2015). Urban design in the Arab world: Reconceptualizing boundaries. Burlington: Ashgate.

Secchi, B. (2005). La Citta' del Ventesimo Secolo. Bari: Edizioni Laterza.

Secchi, B. (2007). Prima Lezione di Urbanistica. Bari: Editori Laterza.

Semm, K., \& Palang, H. (2010). Landscape accessibility: Spaces for accessibility or spaces for communication? Living Reviews in Landscape Research, 4(4).

Shepley, M., Sachs, N., Sadatsafavi, H., Fournier, C., \& Peditto, K. (2019). The impact of green space on violent crime in urban environments: An evidence synthesis. Int. J. Environ. Res. Public Health, 16(24), 5119. https://doi.org/10.3390/ijerph16245119.

Steiner, F. (2011). Landscape ecological urbanism: Origins and trajectories. Landscape and Urban Planning, 100(4), 333-337.

Tadi, M., Biraghi, C. A., \& Zadeh, H. M. (2017). Urban low carbon energy transition: The new porto di mare eco-district in Milan based on IMM methodology. Urbanistica, 160(54), 110-112.

Tan, P. Y., Wang, J., \& Sia, A. (2013). Perspectives on five decades of the urban greening of Singapore. Cities, 32, 24-32. https://doi.org/10.1016/j.cities.2013.02.001. 
Tannous, H., Major, M., \& Furlan, R. (2021). Accessibility of green spaces in a metropolitan network: Using space syntax to objectively evaluate the spatial locations of parks and promenades in Doha, state of Qatar. Urban Forestry \& Urban Greening, 58, 126892. https://doi.org/10.1016/j.ufug.2020.126892.

University, \& Washinghton. (2018). Green Cities: Good Health. Urban Forestry/Urban Greening Research

Wang, P., \& Gonzalez, M. C. (2009). Understanding spatial connectivity of individuals with non-uniform population density. Philosophical Transactions of the Royal Society A, 367, 3321-3329. https://doi. org/10.1098/rsta.2009.0089.

Wiedmann, F., Salama, A., \& Thierstein, A. (2012). Urban Evolution of the City of Doha: An investigation into the impact of economic transformations on urban structures. METU Journal of the Faculty of Architecture, 29(2), 35-61.

Zheng, Q., Zhao, X., \& Jin, M. (2019). Research on urban public green space planning based on taxi data: A case study on three districts of Shenzhen China. Sustainability, 11(4), 1132. https://doi.org/10.3390/ su11041132.

Publisher's Note Springer Nature remains neutral with regard to jurisdictional claims in published maps and institutional affiliations.

\title{
Authors and Affiliations
}

\author{
Raffaello Furlan ${ }^{1}$ (D) B Brian R. Sinclair ${ }^{2}$ \\ Brian R. Sinclair \\ brian.sinclair@ucalgary.ca; brian.sinclair@sinclairstudio.ca \\ 1 Department of Architecture and Urban Planning, College of Engineering, Qatar University, Doha, \\ State of Qatar \\ 2 University of Calgary's School of Architecture, Planning + Landscape (SAPL), Calgary, Canada
}

